\title{
Aesthetic Consciousness of the Linear Language in Costume Design
}

\author{
Jie Yang ${ }^{1, a}$ \\ ${ }^{1}$ School of Art, Hainan University, Haikou, Hainan, China, 570228 \\ ${ }^{a}$ email
}

Keywords: Aesthetic Consciousness, Linear Language, Costume Design

\begin{abstract}
The language of costume design determines the style of clothing tenue. The linear language is an important element in fashion design, because almost every style of design has to be expressed in different linear languages. And the linear language is itself an element with aesthetic tendency, which means the linear language itself has a sense of beauty.
\end{abstract}

\section{Linear Artistic Language Performance}

The linear language is an ancient form of artistic presentation. Abstract words like rhythm, contraction, extension, extrovert, introvert, cheer and serious can be expressed appropriately by the linear language.

Wassily Kandinsky, a Russian artist, systematically analyzed and demonstrated the "linear" language form the perspective of science. He classified "linear" languages as the static, the moving, the musical, the emotional, the organic, the inorganic and others, which is a deep exploration of the linear language in modern art. In the history of modern art, the master of Vienna Secession, Gustav Klimt gave up the concept of massing, strengthened and highlighted the linear language. Therefore he created artistic works with oriental charm, from which we can see that the linear language elements have special morphological and emotional features.

The Linear Language Achieves Its Visual Representation through Specific Morphological Style. According to the research of professional psychological researchers, the feelings towards different linear languages fall into dozens of categories and research about the linear language has deepened to the level of psychological analysis. And the results are interesting: people prefer circular lines, straight lines, wavy lines, elliptical lines, arc lines (affection on the decline). And circular lines, straight lines, wavy lines were most frequently used in prehistoric potteries and hieroglyphics. We can come to the conclusion that the linear language is the basic visual element.

And the linear language is of same significance in costume design.

All clothing design is inseparable from the establishment of basic ideas, such as the basic system of clothing construction: A type, H type, S type, inverted ladder type. First, designers shall build the basic linear frame in his/her consciousness. No matter how complicated the style or pattern is, the designer can make a fast and convenient initial design with the help of the simple and concise linear language.

The Linear Language Elements can reflect the Initial Design of the Designer. The simple and concise linear language is of equal importance even when some mature designers are exploring new styles or possibilities. Therefore linear language elements are more direct and essential than any other elements in reflecting the most basic appearance of the outside world. A tortuous could 
stand for a hill while a circle the sun. The linear language in costume design has a strong visual sense.

In the costume design, linear design for different forms is based on the interior and exterior design of the existing "shape", and these different forms and lines express emotions with abundant variations and diversified characters in the appearance. Because every different line owns its different internal morphological language and emotional language, it also gifts the emotion and association of humans, and makes it equip with the characters of thickness, bending and straightening and directions. As a result, the line in the design has the distinctions of width, thickness, area, shape, color and texture. In the practical costume design applications, in order to reach the art infection with both false and true, sparse and dense, conflicting and convoluted, it usually applies lines comprehensively, such as the repeat of straight and curved lines, the comparison of long and short lines, the pucker of clothing, the decoration line, the button arrangement, which can all produce the sense of beauty in rhythm and pulse.

The ides built on the linear language are unique, distinct and tough. Its innovation will be more complete and thorough. Thus the cognition of linear elements is of great significant in fashion design.

\section{The Differences between Linear Languages in Costume Design}

The linear languages in costume design are based on the satisfiability of ergonomics and basic functions. Professor Obara from Chiba University defines ergonomics as to explore the body's ability to work and its limits so as to adapt occupations to the features of human anatomy, physiology, psychology. The basic functions refer to the convenience of up-straight, walking, elbow shoulder distance, limb width and thickness, activity space of human beings. To study the linear languages in costume design, first we must have a deep understanding about the above satisfiability of ergonomics and basic functions, for that is the cornerstone of rationality of the linear languages. The so-called cornerstone is actually the basic frame or basic constitution. And the cornerstone is on an absolute standard conception at the technical level, based on science. And above the scientific, standard foundation is the artistry of the linear languages. And that is to say, linear languages have duality of cognitive theory. With this understanding, we can pursue the aesthetics of linear languages in specific limited space. The aesthetic consciousness does not come from nowhere.

Tangibility and Intangibility of the Linear Language in Costume Design. As we all know, linear languages in costume design can be classified as vertical, horizontal, diagonal, cross, free, integrated and other basic linear concepts. And these basic concepts show the trends, the presentation of specific morphology. As clothes are worn on human, wrapping their bodies, and bodies are alive, which can perform walking, sitting and other functions, the linear languages are invisible. The clothes wrapping human bodies are consist of invisible lines when people are moving. Designers can't show this in his/her design drafts. However this link does exist. So this is the concept of intangible region. We can understand it as the tendency of linear languages, just like expressing spirit by form in Chinese painting.

In all, that's to transfer the tangibility of linear languages into intangible charm.

Design Ability and Ornamental of the Linear Language in Costume Design. As we discussed earlier, the basic clothing constructions including A type, $\mathrm{H}$ type, S type and inverted ladder type, make up the basic structure. And the basic features including the vertical, horizontal, oblique, crosses, and free type, make up the basic trends. And the structure and trends decide the outline of clothes. On this basis, designers will add dart line, the princess line, shoulder line, arm 
hole, parting line according to the requirements to complete the linear language. Usually designers will add more decorative lines.

The truth is that the basic structure and trends are the most important for linear language.

Let's think about the furnishing style in Qing Dynasty and we may have a better understanding of the importance. The emphasis of Ming furniture is how to extract and refine the linear elements under the basic frame, especially to match suitable type to the structure nodes. However Qing furniture focuses on the complicated carvings and decorations, which ignores the basic structures and trends. From this case, we are aware that when design costumes, the basic structures and trends is not only the basic construction, but also the key to set standard for proportion, length, width, openings and closings. Only in this way, can we find out the inner beauty of linear languages.

\section{Aesthetic consciousness of the Linear Language in Costume Design}

The Aesthetic Consciousness is based on the Quantifiable Feature of Linear Languages. Aesthetic consciousness is a kind of aesthetic category and is purely spiritual feelings. However, aesthetic consciousness of the linear language in costume design is based on the quantifiable feature. It can also be said that beauty consciousness is generated from materiality. Just as the good-looking young teenagers we are looking at, who must reach the standard of materiality and thus generating beauty, aesthetic consciousness is the sublimation of linear languages in costume design. We gain the beauty through materializing the basic structures and trends.

The Linear Language Constitutes the Basic Structures and Trends in Costume Design. Clothing, wrapping human bodies, has dimensionality and measure ability. According to the golden division ratio, there is always a best split point or measure node for the dimension, whether for plane or the three-dimensional. Whatever change or innovation you make, the basic structures and trends may apply to the golden ratio directly or indirectly. Otherwise, it belongs to the non-aesthetic consciousness, which we will have no discussion here. The best split point or measure node for the dimension is an important part for aesthetic consciousness. However, in practice, there is no mathematical template. It may deviate a little bit. So we can grasp the technique through freehand sketching training.

Another rule of aesthetic consciousness is the thinking over natural elements. The seeds of plants, structure law of leaf vein, branches of trees, all these combine the aesthetic with nature.

The presentation of linear language calls for intended long-term accumulation and training. We can see that some outstanding designers can express the charm of clothes with just a few lines when designing some new styles. From their lines, we can feel the strength and width, and that's must be the result of skill training.

The Inheritance and Possibility of the Linear Language in Costume Design. To understand the aesthetic theory about linear languages systematically is of great importance. There is abundant description about lines in traditional Chinese painting: flexible, tangible and intangible, moving and still, hard and soft, deploying and retracting and so on. These are all descriptions about lines, and there is even a classic work Eighteen Method of Sketching.

Wassily Kandinsky, a Russian artist, even brought the linear language to the scientific experimental level. He realized that horizontal lines, vertical lines, and diagonal lines can correspond to black, white and red blocks and expressed it in his works as visual display. There is a serial action of tow powers in linear language and the powers work alternatively. And there is simultaneous action at the same time. 


\section{Conclusion}

The aesthetic consciousness will show off when the linear language is applied in costume design. Issay Miyake, the Japanese master costume designer, who creates oriental linear language with Zen, has a comprehensive inspiration towards oriental linear language and could apply it to his famous designing scheme "pleats please".

Therefore, we have to broaden our horizon of arts, such as the history of classical architectures and paintings from both east and west. And we shall also pay close attention to the modern costume design schools, new materials and technologies. In conclusion, the linear language is the basic and indispensable theory in costume design. And there exist possibility for aesthetic consciousness's to expand and develop.

\section{References}

[1] Ma Lili, Ability and Wisdom, Vol. 8 (2008) No 11, p.217

[2] Niu Min, Xu Qiujie, Journal of Zhejiang Sci-Tech University (Natural Sciences Edition), Vol. 29 (2007) No 11, p.640-645

[3] Tong Ze, Art Education Research, Vol. 6 (2015) No 21, p.84-86

[4] Hu Xiao, Enterprise Economy, Vol. 32 (2011) No 8, p.76-79 